spiders collected. When a wasp has once :chosen a site for building, it is very difficult to drive her away.

63 , St. George Street, Leed;

Hy . LING ROTH

\section{The Microscope as a Refractor}

I AM rather surprised, after the judicious remarks of Dr. Gladstone on this subject in NATURE of July I (p. 192), to find Mr. Gordon Thompson still maintaining his opinion to have introduced anything not yet known or tried with the microscope adapted to this purpose. If he had had time to go over the papers of Royston Pigott (Proceedings of the Royal Society, 1876), of Mr. Sorby (Miniralogical Magazine, 1878), and of myself (Proceedings of the Royal Society, 1884), he could have convinced himself that all what he proposes has been already elaborated and applied. He could also have learnt why the method with the microscope is limited in its exactitude to the third decimal, as the mathematical expression which it involves is deduced from not very strict principles, this being as well the case with the formula for the hollow prism.

The Hague, July 2 I

L. BLEEKRODE

\title{
HERRMANN ABICH
}

$A^{S}$ briefly reported in NATURE last week this venerable geologist died at Vienna on July I. As far back as the year I 83 I he began his scientific career by the publication of an important memoir, in which by novel methods of chemical analysis he determined the composition of various minerals of the Spinel family, and showed how alike by chemical composition and crystalline form they could all be ranged in one group. This early paper gave evidence of the carefulness of observation which distinguished him through life. It was followed by other chemical and mineralogical essays, especially in the department of volcanic products. Gradually he was led to devote special attention to the phenomena of volcanic action, and in the course of his investigations to visit most of the volcanic districts of Europe. His folio atlas of views illustrative of Vesuvius and Etna (1837), and his "Vulkanische Bildungen" (184I), are among the best known of his writings. $\mathrm{He}$ had great facility as a sketcher, and some of his drawings of volcanic craters have done duty for nearly half a century in text-books in many languages. The east of Europe presented a wide and almost unknown field for his exploration. As far back as 1840 he published notices of his wanderings in the Caucasus. He ascended to the summit of Mount Ararat, and devoted most of the remainder of his life to the investigation of the vast region of the Caucasus and south-eastern Europe. Many papers published from time to time in the scientific journals record his unwearied industry. But perhaps the most striking and durable monument of his scientific achievements is his great work, "Geologische Forschungen in den Kaukasischen Ländern," the publication of which he was superintending at the time of his death. This magnificent monograph, of which only the first part has been published, brings before the reader in a series of maps, sketches, large panoramic views, and detailed descriptions a picture of the external aspect and geological structure of the Caucasian region and impresses him with a profound admiration for the author's geological prowess. Abich had during the last few years settled in Vienna, availing himself of the typographic facilities to be found in the Austrian capital. He has been a notable instance of the longevity attained by many active fiel $\downarrow$-geologists, for he almost reached the age of three score and ten years, retaining to the end his enthusiasm and industry. It is to be hoped that the second part of his monumental work, which is to treat of the eastern half of the Armenian Highlands, has been left in such a state as to admit of publication.

\section{CAPILLARY ATTRACTION ${ }^{1}$}

II.

Y OW in this second way we have, in performing the folding motion, allowed the water surface to become less by 60 square centimetres. It is easily seen that, provided the radius of curvature in every part of the surface exceeds one or two hundred times the extent of distance to which the molecular attraction is sensible, or, as we may say practically, provided the radius of curvature is everwhere greater than 5000 micro-millimetres (that is, the two-hundredth of a millimetre), we should have obtained this amount of work with the same diminution of water-surface, however performed. Hence our result is that we have found $45 / 60$ (or $3 / 40$ ) of a centimetre-gramme of work per square centimetre of diminution of surface. This is precisely the result we should have had if the water had been absolutely deprived of the attractive force between water and water, and its whole surface had been coated over with an infinitely thin contractile film possessing a uniform contractile force of $3 / 40$ of a gramme weight, or 75 milligrammes, per lineal centimetre.

It is now convenient to keep to our ideal film, and give

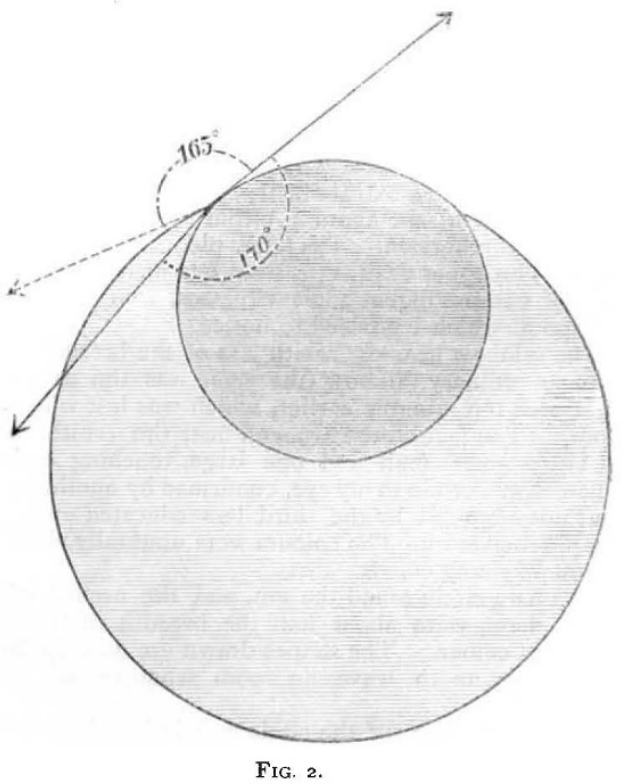

up thinking of what, according to our present capacity for imagining molecular action, is the more real thingnamely, the mutual attraction between the different portions of the liquid. But do not, I entreat you, fall into the paradoxical habit of thinking of the surface film as other than an ideal way of stating the resultant effect of mutual attraction between the different portions of the fluid. Look, now, at one of the pieces of water ideally rigidified, or, if you please, at the two pieces put together to make one. Remember we are at the centre of the earth. What will take place if this piece of matter resting in the air before you suddenly ceases to be rigid? Imagine it, as I have said, to be enclosed in a film everywhere tending to contract with a force equal to $3 / 40$ of a gramme or 75 milligrammes weight per lineal centimetre. This contractile film will clearly press most where the convexity is greatest. A very elementary piece of mathematics tells us that on the rigid convex surface which you see, the amount of its pressure per square centimetre will be found by multiplying the sum ${ }^{2}$ of the curvatures in two mutually-perpendicular normal sections

$x$ Continued from p. 272

2 This sum for brevity I henceforth call simply "the curvature of the surface" at any point. 